\title{
Polymer Nanocomposites Used as Scaffolds for Bone Tissue Regeneration
}

\section{Raquel Couto de Azevedo Gonçalves Mota*, Emerson Oliveira da Silva, Lívia Rodrigues de Menezes}

Instituto de Macromoléculas Professora Eloisa Mano, Universidade Federal do Rio de Janeiro, Rio de Janeiro, Brazil

Email: *raquel@nano.ufrj.br

How to cite this paper: de Azevedo Gonçalves Mota, R.C., da Silva, E.O. and de Menezes, L.R. (2018) Polymer Nanocomposites Used as Scaffolds for Bone Tissue Regeneration. Materials Sciences and Applications, 9, 679-697.

https://doi.org/10.4236/msa.2018.98049

Received: May 17, 2018

Accepted: July 6, 2018

Published: July 9, 2018

Copyright $\odot 2018$ by authors and Scientific Research Publishing Inc. This work is licensed under the Creative Commons Attribution International License (CC BY 4.0).

http://creativecommons.org/licenses/by/4.0/

\begin{abstract}
Scaffolds are three-dimensional biocompatible structures that can mimic the properties of the extracellular matrix (ECM) of a given tissue, like mechanical support and bioactivity, which provides a platform for cellular adherence, proliferation and differentiation. Consequently, scaffolds are frequently used in tissue engineering with the intention of assisting the regeneration of a damaged tissue, and a major application in bone regeneration. An ideal scaffold needs to be biodegradable, biocompatible, and needs to match the biomechanical properties of bone. Polymers are widely used in this field because they fulfil the first two requirements. However, no polymeric material can achieve mechanical properties similar to the bone. For that reason, polymeric nanocomposites, which consist of ceramic/metallic nanoparticles dispersed in a polymer matrix, are being considered for bone scaffold fabrication in order to overcome this problem, since nanoparticles are known to improve composite mechanical strength, and enhance other properties.
\end{abstract}

\section{Keywords}

Scaffolds, Polymer Nanocomposites, Nanoparticles, Bone Tissue Engineering

\section{Introduction}

Aiming to replace traditional technologies in bone fracture treatment, such as grafting and metallic prostheses, the use of biocompatible and biodegradable polymers in bone tissue engineering was developed [1], working as a three-dimensional platform that stimulates and sustains regeneration.

The polymers that are currently in use present advantages like being biocompatible, which avoids an adverse reaction, and biodegradable, which allows for it to disintegrate at the same rate that the bone regenerates, so the scaffold is en- 
tirely replaced by the new tissue [2]. However, they also present the main disadvantage of having lesser mechanical properties in comparison to the bone tissue.

In order to overcome this problem, inspiration was sought out in the very structure of the bone, which can be considered a kind of nanocomposite, since it is made of nanometric components (hydroxyapatite crystals) combined with a micrometric collagen matrix [3]. Thus, inorganic and organic nanometric charges started getting dispersed in the polymeric matrix, with the intention of achieving better properties than those presented by the individual components on their own.

Nanoparticles don't bring benefits solely to the mechanics of the scaffold, they also have a tendency to stimulate cellular adherence, due to their large surface area, playing an important role in bone tissue engineering. Besides that, certain nanoparticles present bactericide and antitumor activities, which bring even more advantages to their use [4].

Hence, the goal of this review paper is to present the state of the art in polymeric nanocomposite use in the medical field, focusing on bone regeneration and detailing the most used polymers and nanoparticles.

\section{Bone Tissue Engineering}

The bone is one of the most rigid tissues in the human body, and is responsible for protecting and providing support to many organs, as well as playing a key role in mobility. That is only possible due to its hierarchical structure, going from firm collagen proteins to rigid minerals such as hydroxyapatite, from the macro to the nanoscale (Figure 1). The function of the bone in the human body is directly linked to its rigidity, which, in turn, is directly proportional to the collagen/mineral percentage of the composite [3]. For instance, long bones show a $20 \%$ collagen/mineral percentage, which is enough for the bone's properties to be adequately balanced, so it can absorb energy and, at the same time, be rigid enough to permit mobility [5].

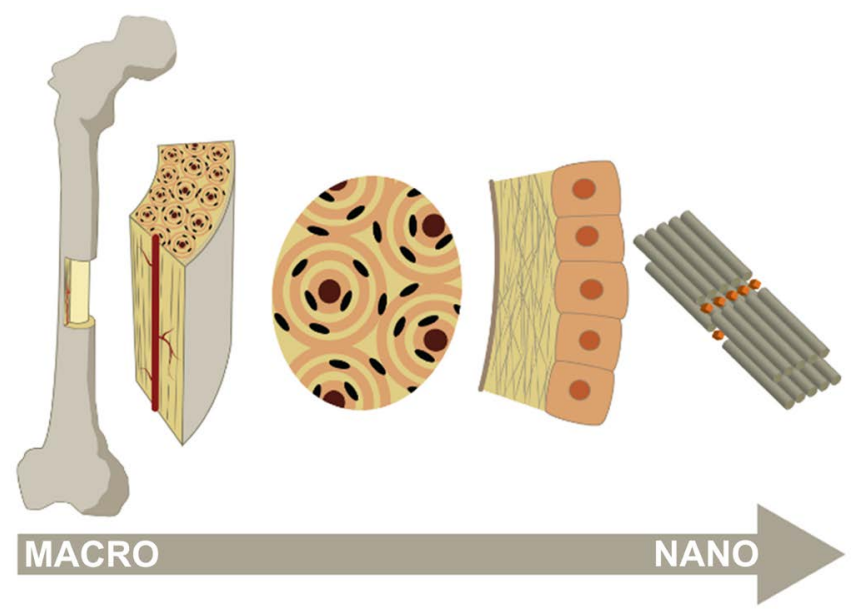

Figure 1. The hierarchical structure of the bone [6]. 
Once the bone is formed, it is dynamically maintained by a remodeling, with constant processes of neoformation and bone reabsorption. These processes are conducted by the bone cells, with osteoblasts being responsible for the former and osteoblasts for the latter [7]. This process happens vigorously during development, but also happens in the adult life, repairing small fractures. For instance, it is normal for $25 \%$ of the trabecular bone, which is the part of the bone that is less dense, and $3 \%$ of the cortical bone, which is the more compact part of the bone, to be removed and substituted every year [8].

This remodeling process is fundamental to the proper functioning of the human body because this process releases ions responsible for the ionic balance of the extracellular fluid, helping to maintain the body's homeostasis and blood $\mathrm{pH}$ [9].

However, this self-rebuilding, which is made possible by the constant bone remodeling, has its limitations regarding bone fractures, and can be divided into two categories: primary and secondary reconstruction. Primary reconstruction happens when the length of the fracture is less than $0.1 \mathrm{~mm}$, which allows ossification through the direct action of osteoclasts and osteoblasts, without the need to involve conjunctive tissue. Secondary bone fracture is the most common form of reconstruction, and it happens when fracture has less than half of the bone's diameter. This process involves several events, including blood clotting, inflammatory response, fibrocartilage formation and, finally, ossification, with the aid of stem cells that differentiate into bone cells [10].

Fractures of larger proportion are not able to spontaneously self-regenerate and require external intervention, which is needed more and more as people grow older and there is a decrease in bone deposition activity. Hence, the need for bone tissue regeneration technology grows dramatically as the world population ages and the life expectancy rates increases [7].

Among the different bone fracture treatments, whether the fracture was due to trauma, old age or illness, the most commonly used is grafting, which is the surgical placement of a bone fragment in the fractured area, stimulating its regeneration. More than two million bone grafting surgeries are performed globally, and bone is the second most transplanted tissue, after blood. The graft can be autogenous, or autograft, being harvested from the patient, allograft, which is harvested from a cadaver, or xenograft, which is bone from another species, such as bovine bone [7].

Autografting has osteoconductive, osteoinductive and osteogenic properties, which allows for fast and complete integration without rejection due to the genic similarity of the grafted tissue. However, one of the problems with the use of this technology is the need to work with two surgical sites, which makes post-op recovery more difficult [11]. Allografting and xenografting are considered an alternative to the discomfort of two surgeries, but these types of grafting are extremely immunogenic, which increases chances of failure as the initial osteoinductive phase can be destroyed by the immunological system and the inflammatory cells, causing necrosis of the osteoconductive cells [12] [13]. 
In order to avoid this adversity, synthetic bone grafts started being used, which means the creation of scaffolds that can temporarily stimulate and support bone regeneration, acting as artificial extracellular matrices that intent to stimulate bone repair. The osteoregeneration process is comprised of three processes: osteoinduction, or the ability to support and facilitate the cellular adherence of osteoblasts and osteoprogenitors; osteoinduction, or the start of the differentiation process of these bone precursors, and osteogenesis, the final part of the bone formation process [9].

\subsection{Main Requisites of Bone Scaffolds}

The ideal scaffold must be biocompatible, biodegradable and bioabsorbable, so it can degrade at the same rate as the neoformation of the bone, so the newly formed tissue is able to replace it. As the scaffold degrades, it loses its mechanical strength, but if that degradation is controlled and takes a long time to happen, the mechanical properties are gradually transferred from the scaffold to the newly formed bone tissue [1].

Another fundamental requisite of scaffolds is degradation with solely non-toxic products that can easily be absorbed or excreted by the body. Besides that, other requisites for the use of scaffolds in bone tissue regeneration include: adequate microstructure, similar mechanical properties to those of the bone tissue from the implanted site and a good interaction in the interface of the cells with the scaffold, in order to allow for cellular adherence, proliferation and differentiation [1].

Thus, through this perspective, the architecture of a scaffold is a fundamental factor for it will determine its microstructure and porosity levels, and the porosity, the size of the pores and the interconnectivity between them will, in turn, determine if cellular and blood infiltration, such as transportation of nutrients and metabolic waste, is possible [14]. Therefore, one of the biggest challenges in the fabrication of scaffolds is the balance between mechanical properties and bioactivity, since these properties are inversely proportional.

In order to evaluate the effect of geometry and porosity in the compressive resistance of these devices, Roohani-esfahani et al. (2016) fabricated ceramic $3 \mathrm{D}$-printed scaffolds, with various porosities $(50 \%, 55 \%, 60 \%, 70 \%)$ and pore shapes (hexagon, curve, rectangular and zigzag). The results allowed the authors to establish that both porosity degree and pore structure significantly alter the scaffold's mechanical properties [15].

Although, under the mechanical perspective, porosity is something that has a negative impact on the scaffold, it's increase is related to a higher bioactivity, because the more a scaffold is porous, the more surface area it has available for cellular adherence and proliferation [16].

In this regard, the study held by Lin and collaborators (2013) aimed to evaluate the relation between scaffold porosity and the cellular activity the scaffold promotes. For that purpose, they made polyethylene glycol (PEG) scaffolds using the stereolithography technique, one of them entirely solid and one with 500 
$\mu \mathrm{m}$ porosity. After a series of tests analyzing cellular activity, it was possible to observe that there was more cellular activity in the porous scaffold than in the solid one. This behavior is due to the largest area available for cellular permeation, since the solid scaffold can only support tissue development on its surface, while the porous one shows the development and proliferation of cells inside its structure, allowing for more extensive tissue repair [16].

Therefore, it can be said that the scaffold's macroporosity plays a major role in bone tissue regeneration since it allows for the scaffold to better integrate with the host tissue. Pores between 100 and $300 \mu \mathrm{m}$ are interesting because it stimulates cellular migration and proliferation [17] [18]. Pores under 100 micrometers, in turn, facilitate the adsorption of nutrients in its surface, and play a key role in the cellular differentiation phase [19] [20] [21] [22].

After studying the porosity of these scaffolds, it can be stipulated that the ideal scaffold would have a porosity degree of between $60 \%$ and $90 \%$ with pores predominantly bigger than 150 micrometers and compression modulus between 100 and $150 \mathrm{MPa}$, to make sure it presents proper mechanical support and bioactivity [15].

Regarding biodegradation time, it is important that the biodegradable scaffolds can maintain their physical properties for at least six months, until the bone tissue regenerates [23] [24]. The elements that impact this process are the intrinsic biodegradation characteristics of each material and the porosity of the scaffolds which increases its surface area, making it easier for fluid to infiltrate the structure, since that directly contributes to its biodegradation [17].

Many techniques can be employed to fabricate porous scaffolds, such as electrospinning [25], solvent casting, porogen leaching [26] [27] and 3-D printing [28] Each one of them has advantages and disadvantages and must be thoroughly studied so that one can choose the most advantageous technique for each particular system. Porogen leaching, for instance, creates systems with the adequate pore dimensions and is currently the most economic method available. However, it is possible to have organic residue in the system, which can cause toxicity and therefore limit its application [29].

3-D printing has brought a plethora of innovations to the tissue regeneration field, because it facilitates higher reproducibility of the technique and better control of the scaffold's architecture and geometry, so that pores with specific sizes and designs are a possibility. However, one of the disadvantages of 3-D printing is the very limited number of materials that can be used. For instance, fused deposition modelling (FDM) and selective laser sintering (SLS) require thermoplastic polymers, while stereolithography (SLA) requires polymers that polymerize with a radical initiator [30].

\subsection{Polymers Used in Bone Tissue Engineering}

Poly (methyl methacrylate) (PMMA) was the first polymer to be used in the orthopedic field and remains one of the most durable materials in bone tissue en- 
gineering due to its high mechanical properties and to the fact that it can be polymerized in situ, which stimulates its application as a cement, aiming to fill in microfractures in the bone. Nonetheless, the application of this polymer in larger fractures is very troublesome, since its mass polymerization is highly exothermic and, in larger quantities, can end up causing damage to surrounding tissue. Other non-degradable polymers, such as polyethylene (PE), polypropylene (PP) and polycarbonate (PC), can also be used in the bone tissue field to permanently replace bone tissue, due to their high mechanical properties and chemical stability. However, as these matrices are non-biodegradable, their application aims to replace bone tissue in areas where tissue cannot be regenerated due to its length or the patient's age [31].

Natural polymers such as collagen [32] [33], fibrin [34], and alginate [35], for instance, are excellent alternative materials for scaffolds because they are bioactive and biocompatible. Among them, collagen is the most used because it is a component of the extracellular matrix and the most abundant protein in the body. However, these natural polymers are limited mostly because of their weak mechanical properties and the possibility to onset immunologic reactions mediated by macrophages [2].

Hence, synthetic biodegradable and biocompatible polymers are being widely studied in regards to their use as scaffold matrices, since they are more easily processed than ceramics and metals and have higher mechanical resistance than natural polymers [36]. Besides, one can have better control of the scaffold's final characteristics, such as crystallinity degree and molar mass, while using these materials.

Polycaprolactone (PCL) is a semi crystalline aliphatic polyester that features satisfactory mechanical properties and degrades into products that can easily be excreted or utilized in the Krebs cycle. PCL's greatest disadvantage, however, is its inheritably hydrophobic chemical nature, which hinders its interaction with bodily fluids and the consequent cellular adherence and proliferation [37].

Polymeric blends and surface coatings can be utilized to alter this undesirable characteristic of PCL. Hence, Shafiee et al. (2013) evaluated PCL blends with poly (vinyl alcohol) (PVA), aiming to reduce the scaffold's hydrophobicity and thus improving its biological interactions. The contact angle analysis between water and the material's surface showed that the PCL/PVA blend can improve the wetness of the structure's surface compared to PCL's, which shows that this maneuver can improve the final scaffold's bioactivity [38]. The polymeric blend can also affect PCL's biodegradation time, which is too high and take up to 3 years' time for molar masses around $\mathrm{M}_{\mathrm{n}} \sim 50000 \mathrm{~g} / \mathrm{mol}$ [39].

Poly (glycolic acid) (PGA) is a highly crystalline polymer $\left(\mathrm{X}_{c}=45 \%-55 \%\right)$ that is usually used as a scaffold due to its high mechanical properties. It was the material used in 1969 by the FDA as the first biodegradable synthetic suture. Regarding biodegradability, PGA starts losing strength in 1-2 months when hydrolyzed and loses mass between 6 - 12 months. Its degradation product, gly- 
cine, can be excreted in urine or converted into carbon dioxide and water through the citric acid cycle [40]. Even though it seems to be a promising matrix for bone tissue application, its main disadvantages are the possibility of causing a local increase of acidy in the surrounding tissue, and its high rigidity, which can complicate its processing [41].

Poly (lactic acid) (PLA) is also a biodegradable and compostable aliphatic polyester. It is a thermoplastic polymer with good mechanical properties. It can be obtained through renewable sources, such as sugarcane, corn and potatoes, with Brazil being the largest sugarcane producer in 2008, having produced $648,921,280$ million tons per year according to the FAO's statistics. It is FDA-approved for use in the biomedical field because not only it is biodegradable, but also biocompatible, and the products of its biodegradation are innocuous to the human body. Besides, the ester groups in its structure undergo hydrolysis, without the need for enzymes, which prevents an inflammatory reaction [42].

Lactic acid is a chiral molecule and it consists of two different isomers, L-D-lactic-acid. Their crystallinity and subsequent chemical and mechanical properties can be controlled through the quantity of $\mathrm{L}$ and $\mathrm{D}$ isomers in its chain. PLLA, for instance, is largely used in tissue engineering for its excellent mechanical properties [43].

This matrix, however, has hydrophobicity and very slow degradation progress as its main disadvantages. Depending on the degree of crystallinity, access to water can be very difficult, which in turn slows down biodegradability [44]. Thus, aiming for a more appropriate biodegradation rate for bone tissue regeneration, one can use a copolymer of PGA with PLA, PGLA, which allows for a better control of biodegradation time, varying the number of monomers during its fabrication. Even though none of the products of PLA and PGA degradation are toxic, they are highly acidic and in large quantities can cause an inflammatory reaction. The fabrication of poly (lactic-co-glycolic acid) (PLGA) makes it possible to better control its biodegradation, accelerate the process and making it so there won't be any inflammatory response [40] [45].

Polyethylene glycol (PEG) is also largely used for this purpose, either by itself or combined to other polymers [46], because it acts as a plasticizer, making its processing easier [29]. It also improves the scaffold's hydrophilicity when combined with hydrophobic polymers such as PLA, PGA and PLGA. It has been proved that PEG and PLLA copolymers show smaller contact angles, going from $71^{\circ}$ to $21^{\circ}$, as the PEG concentration increases [47]. Because of the scaffold's hydrophilicity increase, the biodegradation is also affected, since that process happens through hydrolysis. Thus, the combination of PEG with a hydrophobic polymer accelerates the material's biodegradation, due to the increase in water absorption [41].

Polyhydroxybutyrate (PHB) and other polyhydroxyalkanoates (PHA) are aliphatic polyesters produced by microorganisms in stressful environments 
(lacking nitrogen, oxygen, magnesium phosphate or sulphate). The use of PHA in the bone tissue regeneration field is fairly recent, but has a lot of potential because they are biocompatible. One of the products of their biodegradation is 3-hydroxybutyrate, a blood component that is naturally produced by the liver when breaking down fatty acids. Also, the presence of 3-hydroxybutyrate in the fracture site, as the scaffolds degenerates, causes a higher calcium deposition and keeps bone cell apoptosis and necrosis from happening, which helps with regeneration [48]. Their disadvantage, however, is their limited availability, since they are very expensive to fabricate [39].

PHB is made of repetitive units of 3-hydroxybutyrate, has a high molar mass and is isotactic, due to the stereospecificity of the enzyme responsible for the monomers polymerization, PHB polymerase. Thus, it has the slowest biodegradation rate in the PHA family [48], which limits its use as bone scaffold matrix. Another disadvantage is that, due to its low electronic density, the material cannot absorb enough photons to produce high-contrast images, and so the PHB implants cannot be seen through X rays or CT scans [49].

Chitosan is a polysaccharide derived from chitin, which is biodegradable, biocompatible, non-toxic, and hydrophilic, which makes cellular adherence on its surface easier. Because of that, it is widely used in tissue engineering as a scaffold matrix, or combined with other polymers [50]. Its precursor, chitin, is also used in the biomedical field, both in tissue engineering and drug release, since it is the second most abundant polymer in nature, second only to cellulose, as it can be extracted from the skeletons of maritime crustaceans and insects, while the chitin extracted from maritime sponges has unique biomimetic properties. However, chitin has some opposite properties of those from chitosan, because it is hydrophobic and insoluble both in water and in organic solvents [50].

Both substances, however, present chemical structures similar to those of glycosaminoglycans, main components of the bone's extracellular matrix [51]. Another great advantage of these compounds is that they can easily be processed in different ways, such as gel, microparticle, nanoparticle, nanofiber, etc. And the fact that they have antibacterial and antifungal properties protects the site of the fracture from infection and inflammation, and consequently keeps the scaffold from failing and the patient from being hospitalized. This bactericide property is a result of the polymers cationic nature, which allows for interaction with the microbes' negatively charged membranes. This interaction leads to a drop in osmotic stability, membrane rupture and the eventual departure of intracellular elements [52].

Considering chitosan's affinity to bonding with metallic atoms, especially silver [53], Hajji et al. (2017) tested its bactericide activity and the presence of synergy when chitosan is combined with silver nanoparticles. They fabricated films of PVA-chitosan nanocomposites with silver, CSNF1, CSNF2 and CSNF3, with increasing concentrations of silver, CSNF4 without PVA, and also films with only PVA (PVA 100) and only chitosan (CS 100). They proceeded to measure the area of bacterial inhibition Gram-positive and Gram-negative, and confirmed 
that both the silver and the chitosan had bactericide properties, showing synergy when put together [14].

Considering all of the polymers studied, the best way to fill in all of the requisites of a functional bone scaffold would be to fabricate composites or nanocomposites of biodegradable biocompatible polymer, reinforced with bioactive materials [14], since no polymer can achieve these goals by itself (Figure 2).

\subsection{Nanotechnology}

Nanocomposites have become increasingly more commonplace in bone tissue engineering, since bone tissue itself can be seen as a nanocomposite, with a complex hierarchical structure, made of an organic phase of collagen fibers, and a mineral phase of nanocrystals and hydroxyapatite. Thus, the bone cells react naturally and spontaneously with nanostructured materials, as long as their surface is rough and contains pores of around $2100 \mathrm{~nm}$. This roughness can be mimicked by polymers accompanied by nanoparticles [54].

Besides that, nanomaterials exhibit vastly superior mechanical and osteoconductive properties, due to their larger surface area, which results in higher physicochemical properties, compared to those of the micrometric material. Thus, nanometric surfaces can control cellular functions due to its bioactive surface, making the adherence of osteoblasts easier and promoting their proliferation, stimulating better bone formation than any other conventional material, as many papers have proven [55] [56] [57].

Nanotechnology also makes it possible to make scaffolds more bioactive, because, due to nanoparticles' higher surface area, it is possible to functionalize them with proteins and signifiers that stimulate adherence, proliferation and differentiation of bone cells [4].

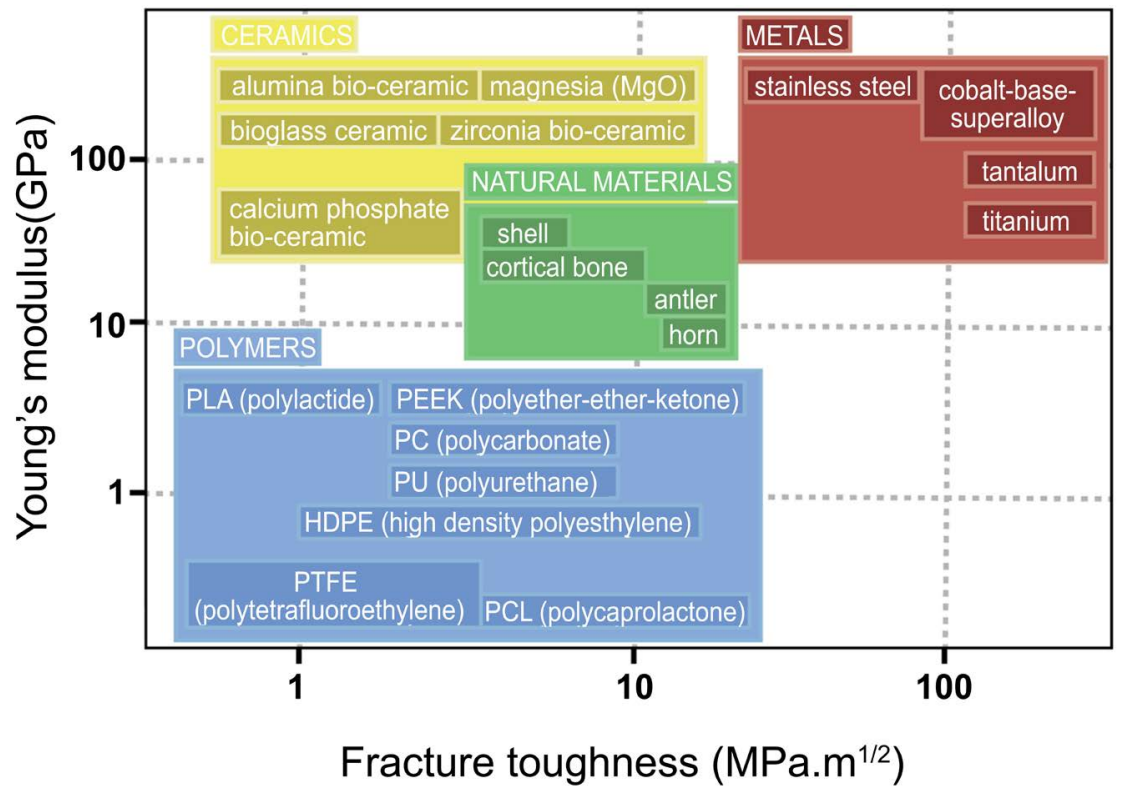

Figure 2. Mechanical properties of natural materials compared to synthetic materials [6]. 
Nanoparticles, especially those that are smaller than $100 \mathrm{~nm}$, have the tendency to form clusters due to the Van Der Walls forces, which rule the nanometric scale. This way, to ensure good results when fabricating a scaffold, it is important to use a technique that guarantees a good dispersion of nanoparticles in the matrix, otherwise the nanoparticles form clusters of micrometric scale, and they lose their nano effect. The better the dispersion, the better the properties shown by the nanocomposite [31].

The use of nanomaterials on biomedicine has also grown as a response to the increasing threat of bacteria capable of developing resistance to antibiotics. Due to the physicochemical properties of nanoparticles, such as larger surface area and smaller size, they have the ability to interact directly with cell membranes of microorganisms and with key protein/enzymes that can inhibit the pathogen's growth or cause apoptosis using a different mechanism than most antibiotics; plus, with the intention of optimizing the bactericide effect of nanoparticles, their size, shape and chemical characteristics can be manipulated [58]. The development of nanoparticles in infection treatment can be divided into two strategies. The first one consists of utilizing materials that have inherent bactericide properties when they're in nanoscale [59]. The second one is the encapsulation of known therapeutics in nanovehicules to improve their efficiency [60].

In 2011, the European Commission defined nanomaterials as natural, accidental or manufactured materials that contain particles, by themselves or in clusters that contain at least one dimension between 1 and $100 \mathrm{~nm}$ [23].

Nanotechnology is among those responsible for the great progress of the biomedical field in the last few years, and, as a consequence, nanomaterials are now being industrially mass produced and some products are being commercialized already [61]. However, there must be caution because up to this moment there have been very few studies about the toxicity of nanomaterials. More information is needed regarding the nanoparticles originating from scaffold degradation, their biomolecule interaction in vivo and possible cluster formation, their capture by macrophages, their entrance in endothelial cells and the resulting toxic effects [62].

\subsection{Nanocomposites}

Ever since 1950, calcium and phosphate ceramics like hydroxyapatite (HA), $\mathrm{Ca}_{10}$ $\left(\mathrm{PO}_{4}\right)_{6}(\mathrm{OH})_{2}$, b-tricalcium phosphate (b-TCP), $\mathrm{Ca}_{3}\left(\mathrm{PO}_{4}\right)_{2}$, and biphasic calcium phosphate $(\mathrm{BCP})$ are widely used in bone tissue engineering because they $\mathrm{mi}-$ mick the minerals that are already in the bone, Thus, these ceramics are absorbable, they show excellent bioconductivity and present mechanical properties similar to those of the human bone [54] [63].

Synthetic hydroxyapatite (HA), in its macro or nanometric form, is a ceramic with osteoconductivity recognized by many studies [64] [65]. It interacts well with the proteins that act on cellular adherence and has direct involvement in cellular differentiation and mineralization. However, HA doesn't have good 
mechanical properties and is extremely brittle, so it is not a good base material of a scaffold. When combined with biodegradable polymeric matrices, mineralization of HA particles in the polymeric surface can be observed. Moeini et al. (2017) made a PCL scaffold with hydroxyapatite to deal with the polymeric matrix's hydrophobicity, and proved that after 14 days of immersion in simulated body fluid (SBF) there was mineralization [66]. Wang et al. (2014) also worked with PCL/nanoHA scaffolds, saw the same effect and theorized that hydroxyapatite nanoparticles' high hydrophilicity enabled the infiltration of water in the scaffold, the hydrolysis of the ester bonds in the polymeric matrix and its subsequent degradation [23].

Other than these advantages, the addition of nanohydroxyapatite can regulate the body's $\mathrm{pH}$, which prevents inflammation in the site of the fracture. The ceramic in nano form can be extracted from bovine sources, bones and fish scales [67].

Metallic particles like silver, zinc, titanium and zirconia show antibacterial and antifungal properties and for that are widely used in the tissue engineering field [53].

Gold and silver nanoparticles are widely used in biomedicine for cancer treatment, especially due to their antitumoral activity. This way, their potential in the bone tissue regeneration field is huge, since it would allow for simultaneous treatment of bone cancer responsible for the bone weakening and subsequent fracturing [68] [69]. Some studies show that these nanoparticles improve mechanical properties and stimulate cell adherence [70] [71] [72].

Zirconium oxide $\left(\mathrm{ZrO}_{2}\right)$ is widely disseminated on the planet, and that included the human body, being present in bone tissue at around $2-20 \mathrm{mg} / \mathrm{kg}$. [73]. Ever since 1970, $\mathrm{ZrO}_{2}$ has been used as a biomedical material due to its versatility. It can be found in the polymorphic forms monoclinic, tetragonal and cubic. It is a biocompatible and bioactive material, and when under stress, its metastable tetragonal phase transforms into the polymorphic monoclinic, closing around the crack, which causes an expansion of its volume and compressive stress and stops the crack from propagating.

In 2013, Liu et al. deposited thin films of zirconium oxide and managed to get not only a great hydroxyapatite deposition via simulated body fluid (SBF), but also great adherence and proliferation of mesenchymal cells, young cartilaginous cells [74].

Titanium oxide $\left(\mathrm{TiO}_{2}\right)$, in turn, is an organic ceramic material that presents three crystal structures: anatase (tetragonal), rutilo (tetragonal) and brookite (orthorhombic) [75], but the brookite form is unstable, and difficult to synthesize, while rutilo and anatase are more widely researched, can be synthesized in laboratories and are semiconductors, showing catalytic activity [76].

Titanium oxides are widely utilized in tissue engineering due to their non-toxicity, low cost, photocatalytic activity, but mostly due to their bactericide properties, which have been studied and reported in many papers. Haldorai et al. 
(2016) have created chitosan nanohybrids with $\mathrm{TiO}_{2}$ to test its bactericide action against E. Coli and had positive results [77].

Zinc is a basic element of the human body, and is present mostly in the bones rather than in other bodily tissues [78]. It is also involved in the regulation, structure and catalysis of alkaline phosphatase (ALP), which plays an important role in osteogenesis and mineralization. It is also believed that zinc has the ability to suppress the osteoclastic reabsorption process [79] [80]. This metal has good compatibility, chemical stability, antibacterial and antifungal activity, with the ability to be non-toxic in vitro and in vivo [62]. Since nanometric zinc oxide exhibits fluorescence, it has been widely utilized in pre-clinical researches, as it is cheap and convenient.

Aiming to improve the mechanical force of the polymers, the nanocharge that shows the biggest potential is carbon nanotube, due to its high mechanical properties and fiber structure. Carbon nanotubes are carbon allotropes in a cylindrical structure, with a ratio of length/diameter of $28,000,000 / 1$. They are characterized as single wall nanotubes (SWNT) and multi-wall nanotubes (MWNT). Most SWNT have a diameter of $1 \mathrm{~nm}$ and exhibit electric properties that are not shared by MWNT, since cellular function is stimulated under an electric current [81].

One of the biggest issues that keeps carbon nanotubes from being disseminated in biomedicine is that their hydrophobic surface, combined with a high aspect ratio, cause agglomeration. That agglomeration of nanotubes causes them to lose the conductive and mechanical properties that made them advantageous in the first place and increases their toxicity. Thus, regarding tissue engineering, it would be ideal to use low concentrations, around $0.5 \% \mathrm{w} / \mathrm{w}$, to avoid agglomeration [82].

In order to go around this problem, the nanotubes are modified, functionalized with the addition of carboxylic groups or alcohol, to help with dispersion in water. However, there is controversy around how this functionalization influences bone regeneration. $\mathrm{Mu}$ et al. (2009) showed that the carboxylic groups inhibit cell proliferation [83]. Other academics, however, claim that the increase in the contact area caused by the reduction of its diameter to nanometric scale improves the interaction with cellular proteins, which in turn compensates the other limitations [84] [85].

Clays are the most used nanocharges in the fabrication of polymeric nanocomposites. Among them, montmorillonite (MMT) stands out. It is a lamellar silicate comprised by an octahedral sheet of alumina between two tetrahedral sheets of silica. Its addition to the polymeric material improves its properties significantly, especially the mechanical ones [86] [87]. This improvement in mechanical properties is attributed to the high aspect ratio of its lamellae, which provides a higher interaction area with the polymer. However, to benefit from this high aspect ratio, the clay must be exfoliated first, which means increasing the interlamellar distance and making sure that the particle is well dispersed in the polymeric matrix through modifiers [88] [89]. 
Due to their high mechanical properties, biocompatibility, biodegradation optimizing effect [90], and their osteoconductive ability [91], clays are very interesting for the biomedical field. However, it's important to verify if the modifiers used to separate the lamellae are biocompatible in order to use them. Ambre et al. (2010) used synthetic amino acids as modifiers, because not only they are biocompatible, but they also have a longer chain than natural amino acids, which made exfoliation easier [89].

\section{Final Considerations}

Polymeric nanocomposites have been widely studied as scaffolds, because the polymers used as matrices are more processable than ceramics and metals, other than being biodegradable and biocompatible. Besides, as bone cells interact naturally with nanostructured materials, the addition of specific nanoparticles in polymeric matrices enhances the biological properties of the scaffolds. Due to their nanometric size, nanoparticles have more surface area, which reflects in better mechanical properties that combined to those of the polymer, can mimick the properties of natural bone. Thus, nanocomposites are widely used in bone tissue regeneration.

However, polymeric nanocomposite scaffolds as fracture treatment are still not in use. There are many challenges to overcome, such as getting adequate dispersion of nanoparticles in the polymeric matrix, and making sure there is a good compatibility between the phases. Besides, there aren't many studies on the toxicity of nanoparticles. Most of the papers that study polymeric nanocomposites as scaffolds don't test in vivo, only in vitro. Thus, it is not possible to achieve a good indication of how the material interacts with the organism and other steps are needed before the final application of the scaffold.

\section{References}

[1] Sheikh, Z., Najeeb, S., Khurshid, Z., Verma, V., Rashid, H. and Glogauer, M. (2015) Biodegradable Materials for Bone Repair and Tissue Engineering Applications. Materials (Basel), 8, 5744-5794. https://doi.org/10.3390/ma8095273

[2] Sargeant, T.D., Desai, A.P., Banerjee, S., Agawu, A. and Stopek, J.B. (2012) An in Situ Forming Collagen-PEG Hydrogel for Tissue Regeneration. Acta Biomaterialia, 8, 124-132. https://doi.org/10.1016/j.actbio.2011.07.028

[3] Seeman, E. (2005) Principles of Bone Biology. 2nd Edition, Academic Press, Orlando.

[4] Stevens, M.M. (2008) Biomaterials for Bone Tissue Engineering. Mater Today, 11, 18-25. https://doi.org/10.1016/S1369-7021(08)70086-5

[5] Agna, J.W., Knowles, H.C. and Alverson, G. (1958) The Mineral Content of Normal Human Bone. Journal of Clinical Investigation, 37, 1357-1361. https://doi.org/10.1172/JCI103725

[6] Mota, R.C.A.G., da Silva, E.O., de Lima, F.F., de Menezes, L.R. and Thiele, A.C.S. (2016) 3D Printed Scaffolds as a New Perspective for Bone Tissue Regeneration: Literature Review. Materials Sciences and Applications, 7, 430-452.

https://doi.org/10.4236/msa.2016.78039 
[7] Ruimerman, R. (2005) Modeling and Remodeling in Bone Tissue. 2nd Edition, Technische Universiteit, Eindhoven.

[8] Wang, W. and Yeung, K.W.K. (2017) Bioactive Materials Bone Grafts and Biomaterials Substitutes for Bone Defect Repair : A Review. Bioact Mater, 2017, 1-24.

[9] Rodan, G.A. (1998) Bone Homeostasis. Proceedings of the National Academy of Sciences of the United States of America, 95, 13361-13362. https://doi.org/10.1073/pnas.95.23.13361

[10] Ghiasi, M.S., Chen, J., Vaziri, A., Rodriguez, E.K. and Nazarian, A. (2017) Bone Fracture Healing in Mechanobiological Modeling: A Review of Principles and Methods. Bone Reports, 6, 87-100. https://doi.org/10.1016/j.bonr.2017.03.002

[11] Roberts, T.T., Rosenbaum, A.J., Roberts, T.T. and Rosenbaum, A.J. (2012) Bone Grafts, Bone Substitutes and Orthobiologics: The Bridge between Basic Science and Clinical Advancements in Fracture Healing. Organogenesis, 8, 114-124. https://doi.org/10.4161/org.23306

[12] Goldberg, V.M. and Akhavan, S. (2005) Biology of Bone Grafts. In: Lieberman, J.R. and Friedlaender, G.E., Eds., Bone Regeneration and Repair, Humana Press, New York, 57-65. https://doi.org/10.1385/1-59259-863-3:057

[13] Wydra, F.B. (2017) Allografts. Clinics in Sports Medicine, 36, 509-523. https://doi.org/10.1016/j.csm.2017.02.007

[14] Tajbakhsh, S. and Hajiali, F.A. (2017) A Comprehensive Study on the Fabrication and Properties of Biocomposites of Poly (Lactic Acid)/Ceramics for Bone Tissue Engineering. Materials Science and Engineering. C, 70, 897-912. https://doi.org/10.1016/j.msec.2016.09.008

[15] Roohani-Esfahani, S.-I., Newman, P. and Zreiqat, H. (2016) Design and Fabrication of 3D Printed Scaffolds with a Mechanical Strength Comparable to Cortical Bone to Repair Large Bone Defects. Scientific Reports, 6, Article ID: 19468. https://doi.org/10.1038/srep19468

[16] Lin, H., Zhang, D., Alexander, P.G., Yang, G., Tan, J., Cheng, A.W.M., et al. (2013) Application of Visible Light-Based Projection Stereolithography for Live Cell-Scaffold Fabrication with Designed Architecture. Biomaterials, 34, 331-339. https://doi.org/10.1016/j.biomaterials.2012.09.048

[17] Bose, S., Vahabzadeh, S. and Bandyopadhyay, A. (2013) Bone Tissue Engineering Using 3D Printing. Materials Today, 16, 496-504.

[18] Murphy, C.M., Haugh, M.G. and Brien, F.J.O. (2010) The Effect of Mean Pore Size on Cell Attachment, Proliferation and Migration in Collagen-Glycosaminoglycan Scaffolds for Bone Tissue Engineering. Biomaterials, 31, 461-466. https://doi.org/10.1016/j.biomaterials.2009.09.063

[19] Barradas, A.M.C., Yuan, H., van Blitterswijk, C.A. and Habibovic, P. (2011) Osteoinductive Biomaterials: Current Knowledge of Properties, Experimental Models and Biological Mechanisms. European Cells and Materials, 21, 407-429. https://doi.org/10.22203/eCM.v021a31

[20] Chang, P., Liu, B., Liu, C., Chou, H., Ho, M., Liu, H., et al. (2007) Bone Tissue Engineering with Novel rhBMP2-PLLA Composite Scaffolds. Journal of Biomedical Materials Research Part A, 81, 771-780. https://doi.org/10.1002/jbm.a.31031

[21] Yuan, H., Yang, Z., Li, Y., Zhang, X., De Bruijn, J.D. and De Groot, K. (1998) Osteoinduction by Calcium Phosphate Biomaterials. Journal of Materials Science: Materials in Medicine, 9, 723-726. https://doi.org/10.1023/A:1008950902047

[22] Perez, R.A. and Mestres, G. (2015) Role of Pore Size and Morphology in Muscu- 
lo-Skeletal Tissue Regeneration. Materials Science and Engineering: C, 61, 922-939. https://doi.org/10.1016/j.msec.2015.12.087

[23] Wang, P., Zhao, L., Liu, J., Weir, M.D., Zhou, X. and Xu, H.H.K. (2014) Bone Tissue Engineering via Nanostructured Calcium Phosphate Biomaterials and Stem Cells. Bone Research, 2, Article ID: 14017. https://doi.org/10.1038/boneres.2014.17

[24] Guo, S.Z., Gosselin, F., Guerin, N., Lanouette, A.M., Heuzey, M.C. and Therriault, D. (2013) Solvent-Cast Three-Dimensional Printing of Multifunctional Microsystems. Small, 9, 4118-4122. https://doi.org/10.1002/smll.201300975

[25] Li, D. and Xia, Y. (2004) Direct Fabrication of Composite and Ceramic Hollow Nanofibers by Electrospinning. Nano Letters, 4, 933-938. https://doi.org/10.1021/nl049590f

[26] Mikos, A.G., Thorsen, A.J., Czerwonka, L.A., Bao, Y., Langer, R., Winslow, D.N., et al. (1994) Preparation and Characterization of Poly (l-Lactic Acid) Foams. Polymer, 35, 1068-1077. https://doi.org/10.1016/0032-3861(94)90953-9

[27] Harris, L.D., Kim, B.S. and Mooney, D.J. (1998) Open Pore Biodegradable Matrices Formed with Gas Foaming. Journal of Biomedical Materials Research, 42, 396-402. https://doi.org/10.1002/(SICI)1097-4636(19981205)42:3<396::AID-JBM7>3.0.CO;2$\underline{\mathrm{E}}$

[28] Hutmacher, D.W., Sittinger, M. and Risbud, M.V. (2004) Scaffold-Based Tissue Engineering: Rationale for Computer-Aided Design and Solid Free-Form Fabrication Systems. Trends in Biotechnology, 22, 354-362. https://doi.org/10.1016/j.tibtech.2004.05.005

[29] Yin, H., Qian, J., Zhang, J., Lin, Z., Li, J., Xu, J., et al. (2016) Engineering Porous Poly (Lactic Acid ) Scaffolds with High Mechanical Performance via a Solid State Extrusion/Porogen Leaching Approach. Polymers, 8, 213. https://doi.org/10.3390/polym8060213

[30] Taboas, J.M., Maddox, R.D., Krebsbach, P.H. and Hollister, S.J. (2003) Indirect Solid Free Form Fabrication of Local and Global Porous, Biomimetic and Composite 3D Polymer-Ceramic Scaffolds. Biomaterials, 24, 181-194. https://doi.org/10.1016/S0142-9612(02)00276-4

[31] de Lacerda Schickert, S. (2014) Polymer-Ceramic Nanocomposites for Bone Regeneration.

[32] Capito, R.M. and Spector, M. (2007) Collagen Scaffolds for Nonviral IGF-1 Gene Delivery in Articular Cartilage Tissue Engineering. Gene Therapy, 14, 721-732. https://doi.org/10.1038/sj.gt.3302918

[33] Liu, Y., Ramanath, H.S. and Wang, D.A. (2008) Tendon Tissue Engineering Using Scaffold Enhancing Strategies. Trends in Biotechnology, 26, 201-209. https://doi.org/10.1016/j.tibtech.2008.01.003

[34] Brown, D.L. (2005) Myocardial Engineering in Vivo: Formation and Characterization of Contractile, Vascularized Three-Dimensional Cardiac Tissue. Tissue Engineering, 11, 803-813.

[35] Rouillard, A.D., Berglund, C.M., Lee, J.Y., Polacheck, W.J., Tsui, Y., Bonassar, L.J., et al. (2011) Methods for Photocrosslinking Alginate Hydrogel Scaffolds with High Cell Viability. Tissue Engineering Part C: Methods, 17, 173-179. https://doi.org/10.1089/ten.tec.2009.0582

[36] Dhandayuthapani, B., Yoshida, Y., Maekawa, T. and Kumar, D.S. (2011) Polymeric Scaffolds in Tissue Engineering Application: A Review. International Journal of Polymer Science, 2011, Article ID: 290602. https://doi.org/10.1155/2011/290602 
[37] Fabbri, P., Bondioli, F., Messori, M., Bartoli, C., Dinucci, D. and Chiellini, F. (2010) Porous Scaffolds of Polycaprolactone Reinforced with in Situ Generated Hydroxyapatite for Bone Tissue Engineering. Journal of Materials Science: Materials in Medicine, 21, 343-351. https://doi.org/10.1007/s10856-009-3839-5

[38] Shafiee, A., Soleimani, M., Chamheidari, G.A., Seyedjafari, E., Dodel, M., Atashi, A., et al. (2011) Electrospun Nanofiber-Based Regeneration of Cartilage Enhanced by Mesenchymal Stem Cells. Journal of Biomedical Materials Research Part A, 99, 467-478.

[39] Rezwan, K., Chen, Q.Z., Blaker, J.J. and Roberto, A. (2006) Biodegradable and Bioactive Porous Polymer/Inorganic Composite Scaffolds for Bone Tissue Engineering. Biomaterials, 27, 3413-3431. https://doi.org/10.1016/j.biomaterials.2006.01.039

[40] Velasco, M.A., Narváez-Tovar, C.A. and Garzón-Alvarado, D.A. (2015) Design, Materials , and Mechanobiology of Biodegradable Scaffolds for Bone Tissue Engineering. BioMed Research International, 2015, Article ID: 729076.

[41] Kutikov, A. and Song, J. (2015) Biodegradable PEG-Based Amphiphilic Block Copolymers for Tissue Engineering Applications. ACS Biomaterials Science \& Engineering, 1, 463-480.

[42] Lasprilla, A.J.R., Martinez, G.A.R., Lunelli, B.H., Jardini, A.L. and Maciel, R. (2012) Poly-Lactic Acid Synthesis for Application in Biomedical Devices-A Review. Biotechnology Advances, 30, 321-328. https://doi.org/10.1016/j.biotechadv.2011.06.019

[43] Lunt, J. (1998) Large-Scale Production, Properties and Commercial Applications of Polylactic Acid Polymers. Polymer Degradation and Stability, 59, 145-152. https://doi.org/10.1016/S0141-3910(97)00148-1

[44] Lopes, M.S., Jardini, A.L. and Filho, R.M. (2012) Poly (Lactic Acid) Production for Tissue Engineering Applications, Procedia Engineering, 42, 1402-1413.

[45] Stratton, S., Shelke, N.B., Hoshino, K., Rudraiah, S. and Kumbar, S.G. (2016) Bioactive Polymeric Scaffolds for Tissue Engineering. Bioactive Materials, 1, 93-108. https://doi.org/10.1016/j.bioactmat.2016.11.001

[46] Zhu, J. (2010) Bioactive Modification of Poly (Ethylene Glycol) Hydrogels for Tissue Engineering. Biomaterials, 31, 4639-4656. https://doi.org/10.1016/j.biomaterials.2010.02.044

[47] Kutikov, A.B. and Song, J. (2013) An Amphiphilic Degradable Polymer/Hydroxyapatite Composite with Enhanced Handling Characteristics Promotes Osteogenic Gene Expression in Bone Marrow Stromal Cells. Acta Biomaterialia, 9, 8354-8364. https://doi.org/10.1016/j.actbio.2013.06.013

[48] Lim, J., You, M., Li, J. and Li, Z. (2017) Emerging Bone Tissue Engineering via Polyhydroxyalkanoate (PHA)-Based Scaffolds. Materials Science and Engineering. $C$, 79, 917-929. https://doi.org/10.1016/j.msec.2017.05.132

[49] Meischel, M., Eichler, J., Martinelli, E., Karr, U., Weigel, J., Schmöller, G., et al. (2016) Adhesive Strength of Bone-Implant Interfaces and in Vivo Degradation of PHB Composites for Load-Bearing Applications. Journal of the Mechanical Behavior of Biomedical Materials, 53, 104-118.

https://doi.org/10.1016/j.jmbbm.2015.08.004

[50] Lowe, B., Venkatesan, J., Anil, S., Shim, M.S. and Kim, S.K. (2016) Preparation and Characterization of Chitosan-Natural Nano Hydroxyapatite-Fucoidan Nanocomposites for Bone Tissue Engineering. International Journal of Biological Macromolecules, 93, 1479-1487. https://doi.org/10.1016/j.ijbiomac.2016.02.054

[51] Deepthi, S., Venkatesan, J., Kim, S.-K., Bumgardner, J.D. and Jayakumar, R. (2016) An Overview of Chitin or Chitosan/Nano Ceramic Composite Scaffolds for Bone Tissue Engineering. International Journal of Biological Macromolecules, 93, 1338-1353. 
https://doi.org/10.1016/j.ijbiomac.2016.03.041

[52] Friedman, A.J., Phan, J., Schairer, D., Champer, J., Qin, M., Pirouz, A., et al. (2013) Antimicrobial and Anti-Inflammatory Activity of Chitosan-Alginate Nanoparticles: A Targeted Therapy for Cutaneous Pathogens. Journal of Investigative Dermatology, 133, 1231-1239. https://doi.org/10.1038/jid.2012.399

[53] Saravanan, S., Nethala, S., Pattnaik, S., Tripathi, A., Moorthi, A. and Selvamurugan, N. (2011) Preparation, Characterization and Antimicrobial Activity of a Bio-Composite Scaffold Containing Chitosan/Nano-Hydroxyapatite/Nano-Silver for Bone Tissue Engineering. International Journal of Biological Macromolecules, 49, 188-193. https://doi.org/10.1016/j.ijbiomac.2011.04.010

[54] Zwingenberger, S., Nich, C., Valladares, R.D., Yao, Z., Stiehler, M. and Goodman, S.B. (2012) Recommendations and Considerations for the Use of Biologics in Orthopedic Surgery. BioDrugs, 26, 245-256. https://doi.org/10.1007/BF03261883

[55] Wei, J., Hong, H., Wu, L., He, Y. and Li, Y.B. (2007) Preliminary Investigation of Bioactivity of Nano Biocomposite. Journal of Materials Science: Materials in Medicine, 18, 529-533. https://doi.org/10.1007/s10856-007-2014-0

[56] Schneider, O.D., Loher, S., Brunner, T.J., Uebersax, L., Simonet, M., Grass, R.N., et al. (2007) Cotton Wool-Like Nanocomposite Biomaterials Prepared by Electrospinning: In Vitro Bioactivity and Osteogenic Differentiation of Human Mesenchymal Stem Cells. Journal of Biomedical Materials Research Part B: Applied Biomaterials, 84B, 350-362.

[57] Bernhardt, A., Lode, A., Boxberger, S., Pompe, W. and Gelinsky, M. (2008) Mineralised Collagen-An Artificial, Extracellular Bone Matrix-Improves Osteogenic Differentiation of Bone Marrow Stromal Cells. Journal of Materials Science: Materials in Medicine, 19, 269-275. https://doi.org/10.1007/s10856-006-0059-0

[58] Blecher, K., Nasir, A. and Friedman, A. (2011) The Growing Role of Nanotechnology in Combating Infectious Disease. Virulence, 2, 395-401. https://doi.org/10.4161/viru.2.5.17035

[59] Hemmila, M.R., Mattar, A., Taddonio, M.A. and Arbabi, S. (2011) Topical Nanoemulsion Therapy Reduces Bacterial Wound Infection and Inflammation after Burn Injury. Surgery, 148, 499-509. https://doi.org/10.1016/j.surg.2010.01.001

[60] Domínguez-Delgado, C.L., Rodríguez-Cruz, I.M., Escobar-Chávez, J.J., Calderón-Lojero, I.O., Quintanar-Guerrero, D. and Ganem, A. (2011) Preparation and Characterization of Triclosan Nanoparticles Intended to Be Used for the Treatment of Acne. European Journal of Pharmaceutics and Biopharmaceutics, 79, 102-107. https://doi.org/10.1016/j.ejpb.2011.01.017

[61] Mothersill, C. and Seymour, C.B. and O'Brien, A. (1991) Induction of C-Myc Oncoprotein and of Cellular Proliferation by Radiation in Normal Human Urothelial Cultures. Anticancer Research, 11, 1609-1612.

[62] Zhang, Y., Nayak, R.T., Hong, H. and Cai, W. (2014) Biomedical Applications of Zinc Oxide Nanomaterials. Current Molecular Medicine, 13, 1633-1645. https://doi.org/10.2174/1566524013666131111130058

[63] Malhotra, A. and Habibovic, P. (2016) Calcium Phosphates and Angiogenesis : Implications and Advances for Bone Regeneration. Trends in Biotechnology, 34, 983-992. https://doi.org/10.1016/j.tibtech.2016.07.005

[64] Nichols, H.L., Zhang, N., Zhang, J., Shi, D., Bhaduri, S. and Wen, X. (2007) Coating Nanothickness Degradable Films on Nanocrystalline Hydroxyapatite Particles to Improve the Bonding Strength between Nanohydroxyapatite and Degradable Polymer Matrix. Journal of Biomedical Materials Research Part A, 82A, 373-382. 
[65] Zhou, H. and Lee, J. (2011) Nanoscale Hydroxyapatite Particles for Bone Tissue Engineering. Acta Biomaterialia, 7, 2769-2781. https://doi.org/10.1016/j.actbio.2011.03.019

[66] Moeini, S., Mohammadi, M.R. and Simchi, A. (2017) In-Situ Solvothermal Processing of Polycaprolactone/Hydroxyapatite Nanocomposites with Enhanced Mechanical and Biological Performance for Bone Tissue Engineering. Bioactive Materials, $\mathbf{x x x}, 1-10$.

[67] Venkatesan, J., Lowe, B., Manivasagan, P., Kang, K.H., Chalisserry, E.P., Anil, S., et al. (2015) Isolation and Characterization of Nano-Hydroxyapatite from Salmon Fish Bone. Materials, 8, 5426-5439. https://doi.org/10.3390/ma8085253

[68] Patrascu, J.M., Nedelcu, I.A., Sonmez, M., Ficai, D., Ficai, A., Vasile, B.S., et al. (2015) Composite Scaffolds Based on Silver Nanoparticles for Biomedical Applications. Journal of Nanomaterials, 2015, Article ID: 587989.

[69] Vial, S., Reis, R.L. and Oliveira, J.M. (2017) Recent Advances Using Gold Nanoparticles as a Promising Multimodal Tool for Tissue Engineering and Regenerative Medicine. Current Opinion in Solid State and Materials Science, 21, 92-112. https://doi.org/10.1016/j.cossms.2016.03.006

[70] Heo, D.N., Ko, W.-K., Bae, M.S., Lee, J.B., Lee, D.-W., Byun, W., et al. (2014) Enhanced Bone Regeneration with a Gold Nanoparticle-Hydrogel Complex. Journal of Materials Chemistry B, 2, 1584-1593. https://doi.org/10.1039/C3TB21246G

[71] Patel, N.G., Kumar, A., Jayawardana, V.N., Woodworth, C.D. and Yuya, P.A. (2014) Fabrication, Nanomechanical Characterization, and Cytocompatibility of Gold-Reinforced Chitosan Bio-Nanocomposites. Materials Science and Engineering: $C$, 44, 336-344. https://doi.org/10.1016/j.msec.2014.08.042

[72] Marsich, E., Bellomo, F., Turco, G., Travan, A., Donati, I. and Paoletti, S. (2013) Nano-Composite Scaffolds for Bone Tissue Engineering Containing Silver Nanoparticles: Preparation, Characterization and Biological Properties. Journal of Materials Science: Materials in Medicine, 24, 1799-1807. https://doi.org/10.1007/s10856-013-4923-4

[73] Ghosh, S., Sharma, A. and Talukder, G. (1992) Zirconium an Abnormal Trace Element in Biology. Biological Trace Element Research, 35, 241-271.

[74] Liu, Y.T., Lee, T.M. and Lui, T.-S. (2013) Enhanced Osteoblastic Cell Response on Zirconia by Bio-Inspired Surface Modification. Colloids Surfaces B: Biointerfaces, 106, 37-45. https://doi.org/10.1016/j.colsurfb.2013.01.023

[75] Mourão, H.A.J.L., de Mendonça, V.R., Malagutti, A.R. and Ribeiro, C. (2009) Nanoestruturas em fotocatálise: Uma revisão sobre estratégias de síntese de fotocatalisadores em escala nanométrica. Química Nova, 32, 2181-2190. https://doi.org/10.1590/S0100-40422009000800032

[76] Costa, A.C.F.M., Vilar, M.A., Lira, H.L., Kiminami, R.H.G.A., Gama, L., Federal, U., et al. (2006) Síntese e caracterização de nanopartículas de $\mathrm{TiO}_{2}$ (Synthesis and Characterization of $\mathrm{TiO}_{2}$ Nanoparticles). Cerâmica, 52, 255-259. https://doi.org/10.1590/S0366-69132006000400007

[77] Haldorai, Y. and Shim, J. (2014) Novel Chitosan- $\mathrm{TiO}_{2}$ Nanohybrid: Preparation, Characterization, Antibacterial, and Photocatalytic Properties. Polymer Composites, 35, 327-333. https://doi.org/10.1002/pc.22665

[78] Coleman, J.E. (1992) Structure and Mechanism of Alkaline Phosphatase. Annual Review of Biophysics and Biomolecular Structure, 21, 441-483. https://doi.org/10.1146/annurev.bb.21.060192.002301

[79] Yamaguchi, M. (1998) Role of Zinc in Bone Formation and Bone Resorption. The 
Journal of Trace Elements in Experimental Medicine, 11, 119-135. https://doi.org/10.1002/(SICI)1520-670X(1998)11:2/3<119::AID-JTRA5>3.0.CO;2-3

[80] Yamaguchi, M. (2007) Role of Zinc in Bone Metabolism and Preventive Effect on Bone Disorder. Biomedical Research on Trace Elements, 18, 346-366.

[81] Sahithi, K., Swetha, M., Ramasamy, K., Srinivasan, N. and Selvamurugan, N. (2010) Polymeric Composites Containing Carbon Nanotubes for Bone Tissue Engineering. International Journal of Biological Macromolecules, 46, 281-283. https://doi.org/10.1016/j.ijbiomac.2010.01.006

[82] Newman, P., Minett, A., Ellis-Behnke, R. and Zreiqat, H. (2013) Carbon Nanotubes: Their Potential and Pitfalls for Bone Tissue Regeneration and Engineering. Nanomedicine: Nanotechnology, Biology and Medicine, 9, 1139-1158.

https://doi.org/10.1016/j.nano.2013.06.001

[83] Mu, Q., Du, G., Chen, T., Zhang, B. and Yan, B. (2009) Suppression of Human Bone Morphogenetic Protein Signaling by Carboxylated Single-Walled Carbon Nanotubes. ACS Nano, 3, 1139-1144. https://doi.org/10.1021/nn900252j

[84] Li, X., Liu, H., Niu, X., Yu, B., Fan, Y., Feng, Q., et al. (2012) The Use of Carbon Nanotubes to Induce Osteogenic Differentiation of Human Adipose-Derived MSCs in Vitro and Ectopic Bone Formation in Vivo. Biomaterials, 33, 4818-4827. https://doi.org/10.1016/j.biomaterials.2012.03.045

[85] Shannahan, J.H., Brown, J.M., Chen, R., Ke, P.C., Lai, X., Mitra, S., et al. (2013) Comparison of Nanotube-Protein Corona Composition in Cell Culture Media. Small, 9, 2171-2181. https://doi.org/10.1002/smll.201202243

[86] Marras, S.I., Kladi, K.P., Tsivintzelis, I., Zuburtikudis, I. and Panayiotou, C. (2008) Biodegradable Polymer Nanocomposites: The Role of Nanoclays on the Thermomechanical Characteristics and the Electrospun Fibrous Structure. Acta Biomaterialia, 4, 756-765. https://doi.org/10.1016/j.actbio.2007.12.005

[87] Zanetti, M., Sergei, L. and Camino, G. (2000) Polymer Layered Silicate Nanocomposites. Macromolecular Materials and Engineering, 279, 1-9. https://doi.org/10.1002/1439-2054(20000601)279:1<1::AID-MAME1>3.0.CO;2-Q

[88] Ambre, A.H., Katti, D.R. and Katti, K.S. (2015) Biomineralized Hydroxyapatite Nanoclay Composite Scaffolds with Polycaprolactone for Stem Cell-Based Bone Tissue Engineering. Journal of Biomedical Materials Research Part A, 103, 2077-2101. https://doi.org/10.1002/jbm.a.35342

[89] Ambre, A.H., Katti, K.S. and Katti, D.R. (2010) Nanoclay Based Composite Scaffolds for Bone Tissue Engineering Applications. Accepted Manuscripts Journal of Nanotechnology in Engineering and Medicine, 1, Article ID: 31013. https://doi.org/10.1115/1.4002149

[90] Gaharwar, A.K., Mukundan, S., Karaca, E., Dolatshahi-Pirouz, A., Patel, A., Rangarajan, K., et al. (2014) Nanoclay-Enriched Poly(E-Caprolactone) Electrospun Scaffolds for Osteogenic Differentiation of Human Mesenchymal Stem Cells. Tissue Engineering Part A, 20, 1-14. https://doi.org/10.1089/ten.tea.2013.0281

[91] Gaharwar, A.K., Mihaila, S.M., Swami, A., Patel, A., Sant, S., Reis, R.L., et al. (2013) Bioactive Silicate Nanoplatelets for Osteogenic Differentiation of Human Mesenchymal Stem Cells. Advanced Materials, 25, 3329-3336.

https://doi.org/10.1002/adma.201300584 